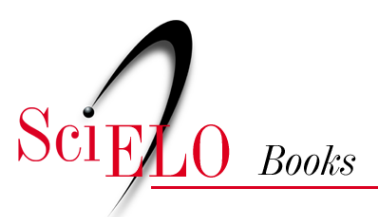

\title{
26 Tribo Heliantheae Cass.
}

\author{
Mara Angelina Galvão Magenta \\ João Bernardo de A. Bringel Jr. \\ Maria Alves
}

MAGENTA, M.A.G., BRINGEL JR., J.B.A., and ALVES, M. Tribo Heliantheae Cass. In: ROQUE, N. TELES, A.M., and NAKAJIMA, J.N., comp. A família Asteraceae no Brasil: classificação e diversidade [online]. Salvador: EDUFBA, 2017, pp. 185-195. ISBN: 978-85-232-1999-4.

https://doi.org/10.7476/9788523219994.0028.

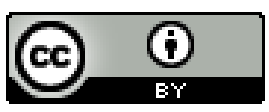

All the contents of this work, except where otherwise noted, is licensed under a Creative Commons Attribution 4.0 International license.

Todo o conteúdo deste trabalho, exceto quando houver ressalva, é publicado sob a licença Creative Commons Atribição 4.0.

Todo el contenido de esta obra, excepto donde se indique lo contrario, está bajo licencia de la licencia Creative Commons Reconocimento 4.0. 


\section{TRIBO HELIANTHEAE CASS.}

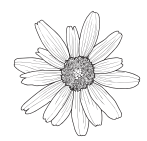

Mara Angelina Galvão Magenta

João Bernardo de A. Bringel Jr.

Maria Alves

A partir de estudos filogenéticos moleculares (PANERO; FUNK, 2002), Heliantheae sensu stricto foi recircunscrita incluindo a maioria dos táxons com receptáculo paleáceo e uma ampla diversidade de representantes lenhosos da Aliança Heliantheae (BALDWIN, 2009).

A caracterização morfológica da tribo, no entanto, é uma tarefa difícil devido ao elevado número de homoplasias morfológicas (PANERO, 2007). Contudo, seus representantes podem ser reconhecidos por um conjunto de características, como as brácteas involucrais frequentemente foliáceas, capítulos com receptáculo geralmente contendo páleas conduplicadas, quase sempre persistentes e envolvendo as flores do disco, anteras com apêndice geralmente oval e cipselas compressas com paredes impregnadas de fitomelanina (substância presente na maioria das tribos da Aliança Heliantheae, com exceção de Helenieae) (BALDWIN, 2009).

O sistema de classificação proposto por Panero (2007) divide Heliantheae em 14 subtribos, 113 gêneros e aproximadamente 1.500 espécies, com distribuição pantropical, em especial no México e nas Américas Central e do Sul.

\section{Descrição}

Ervas anuais ou perenes, arbustos, lianas ou árvores. Folhas alternas ou opostas, lâminas geralmente simples, raramente divididas, a maioria 
oval, 3-nervada, face adaxial geralmente escábrida. Capitulescência paniculiforme ou corimbiforme, terminal ou raramente axial, às vezes capítulos solitários em pedúnculos longos ou raramente sésseis; invólucros cilíndricos ou hemisféricos. Capítulos radiados, discoides, raramente disciformes, heterógamos ou homógamos; brácteas involucrais similares em 1-7 séries, geralmente as mais internas menores, paleáceas; receptáculo geralmente com páleas, às vezes reflexas ou patentes. Flores do raio 5-13(-21+), raramente 1 ou 2, pistiladas, férteis, estéreis ou neutras, corolas às vezes sem tubo, limbo com ápice 3-lobado, às vezes 2-lobado; flores do disco bissexuais ou funcionalmente estaminadas, raramente funcionalmente pistiladas, corola actinomorfa, raramente zigomorfa, campanulada ou urceolada, gradual ou abruptamente expandida acima do tubo; estames 5, raramente 4(-3), filetes glabros, raramente papilosos, anteras conatas ou livres, apêndices do conectivo geralmente ovais; ramos do estilete geralmente com 1 tufo apical de papilas. Cipselas do raio levemente trigonais e compressas, lisas ou estriadas, aladas ou sem alas; cipselas do disco geralmente compressas, biconvexas ou raramente levemente quadrangulares, estreita a largamente obovais ou levemente orbiculares, cilíndricas, prismáticas, estriadas ou não, enegrecidas; pápus de aristas (Figuras 17N-O) persistentes e com escamas, às vezes reduzido ou caduco, ou raramente sem pápus.

No Brasil, ocorrem 38 gêneros e cerca de 228 espécies, sendo cerca de 122 endêmicas. Dentre os gêneros com registros para o Brasil, 10 apresentam apenas espécies naturalizadas (Blainvillea Cass., Calyptocarpus Less., Eleutheranthera Poit. ex Bosc, Lagascea Cav., Parthenium L., Synedrella Gaertn., Synedrellopsis Hieron. \& Kuntze ex Kuntze, Tithonia Desf. ex Juss., Xanthium L. e Zinnia L.). Os gêneros Echinacea Moench, Helianthus L., Montanoa Cerv., Perymenium Schrad., Rudbeckia L. e Sanvitalia Lam. são conhecidos apenas por espécies cultivadas no país. Os gêneros Borrichia Adans., Sclerocarpus Jacq. e Oblivia Strother são conhecidos no Brasil por poucos registros de herbário de forma que ainda restam dúvidas quanto à origem. A proposta de Robinson (1992) de sinonimizar Aspilia Thouars em Wedelia Jacq. é controversa, já que ainda são necessários estudos filogenéticos para esclarecer o status das espécies brasileiras; por isso, esses gêneros foram considerados distintos, como vários autores têm sugerido, a exemplo de Santos (2001), Silva e Santos 
(2010), Hind (2011) e Flora do Brasil 2020 (em construção). Representantes de Heliantheae estão destacados nas Figuras 19D-H e 21A-H.

\section{Chave de identificação para os gêneros de Heliantheae no Brasil}

1. Planta com 2 tipos de capítulo: capítulos apenas com flores pistiladas e capítulos apenas com flores funcionalmente estaminadas............................. 2 1'. Planta com um único tipo de capítulo (Figura 17K) ..................................... 3

2. Brácteas involucrais dos capítulos funcionalmente estaminados conatas; capítulos pistilados com 1 flor; cipselas involucradas, ápice geralmente com projeções espinescentes (Figura 17J) Ambrosia 2'. Brácteas involucrais dos capítulos funcionalmente estaminados livres; capítulos pistilados com 2 flores; cipselas não involucradas, coberta por cerdas uncinadas (Figura 20H) Xanthium

3. Flores do raio com filamentos marginais ligados às páleas de 2 flores do disco (Figura 20C) Parthenium 3'. Flores do raio livres das páleas e flores do disco

4. Capítulos disciformes; corola geralmente com ductos resiníferos levemente avermelhados ao longo das nervuras

4'. Capítulos discoides, radiados ou raramente disciformes; corola com ductos resiníferos não avermelhados ao longo das nervuras 6

5. Capítulos com 1 flor pistilada, invólucro epaleáceo; lobos das flores do disco com tricomas longos e rígidos (Figura 20D); cipselas dispersadas com invólucro (cipselas involucradas) Riencourtia 5'. Capítulos com mais de 2 flores pistiladas; lobos da corola sem tricomas longos; cipselas dispersadas sem invólucro. Clibadium

6. Capitulescência de capítulos agrupados (Figura 20A); capítulos quase sempre unifloros (Figura 20B); brácteas involucrais unidas na base, formando um tubo Lagascea 6'. Capitulescência de capítulos não agrupados; capítulos nunca unifloros; brácteas involucrais livres 7 
7. Ápice das brácteas involucrais com faixa azul-escura ou enegrecida; corola da flor do raio fundida à cipsela (Figura 20I) Zinnia 7'. Ápice das brácteas involucrais sem faixa azul-escura ou enegrecida; corola da flor do raio não fundida à cipsela

8. Receptáculo convexo a cônico, tornando-se fortemente cônico a colunar na maturidade. 9

8'. Receptáculo plano ou convexo, não aumentando na maturidade ... 13

9. Arbustos eretos a escandentes; lâmina foliar coriácea, capitulescências corimbiformes Salmea

9'. Ervas eretas; lâmina foliar membranácea ou cartácea, capítulos solitários ou em capitulescência formando cimeira laxa... 10

10. Folhas opostas; flores do raio, quando presentes, pistiladas; cipselas ciliadas, pápus 2-aristado, com 2 escamas ou, raramente, com poucas cerdas macias

10'. Folhas alternas; flores do raio neutras; cipselas sem cílios, sem pápus ou com pápus diminuto, coroniforme ou de 2-4 escamas 12

11. Folhas sésseis ou subsésseis; cipselas com margem corticosa conspícua, pápus de aristas delicadas ou sem pápus Spilanthes 11'. Folhas com pecíolo conspícuo; cipselas sem margem corticosa ou, às vezes, com margem corticosa inconspícua, pápus de aristas robustas, levemente espessas na base (Figura 17I). Acmella

12. Páleas com ápice rígido, pontiagudo ou arredondado Echinacea 12’. Páleas sem ápice rígido Rudbeckia

13. Corolas das flores do raio sem tubo. 14

13'. Corolas das flores do raio, quando presentes, com tubo. 16

14. Arbustos decumbentes ou eretos; pápus coroniforme Borrichia 14'. Ervas eretas ou prostadas ou arbustos escandentes, raramente arbustos eretos; pápus aristado ou ausente 
15. Corolas das flores do raio com lâminas planas; cipselas das flores do raio com tricomas uncinados Sanvitalia 15'. Corolas das flores do raio com lâminas involutas; cipselas das flores do raio com tricomas, quando presentes, de outros tipos Oblivia

16. Brácteas involucrais em 1 série. 17

16’. Brácteas involucrais em 2 ou mais séries (1-2 em Melanthera). 20

17. Páleas envolvendo completamente as flores; cipselas dispersadas com as páleas do receptáculo enrijecidas Sclerocarpus 17’. Páleas conduplicadas ou ausentes; cipselas dispersadas sem as páleas do receptáculo. 18

18. Invólucro com 2 brácteas involucrais; cipselas com alas laceradas Synedrellopsis 18’. Invólucro com 3 ou mais brácteas involucrais; cipselas sem alas 19

19. Invólucro com cerca de 5 brácteas involucrais semelhantes entre si; cipselas maduras com margem rugosa, com pápus coroniforme

Eleutheranthera

19'. Invólucro de 3-(4) brácteas involucrais, uma grande e arredondada, foliácea, 2 menores, escariosas (Figura 15P); cipselas maduras com margem lisa, sem pápus

Delilia

20. Receptáculo com páleas filiformes; flores do raio geralmente lineares (Figuras 15L-M). Eclipta

20'. Receptáculo com páleas de outras formas; flores do raio de outros formatos. 21

21. Cipselas sem pápus, com pápus coroniforme inconspícuo ou com pápus de cerdas 22 21'. Cipselas com pápus coroniforme conspícuo ou de aristas ou escamas .

22. Cipselas maduras com superfície carnosa Tilesia

22'. Cipselas maduras com superfície seca 23 
23. Páleas do receptáculo com ápice alargado, espinescente; flores do raio de cor diferente das flores do disco; cipselas obovoides compressas, 2-gonais, presas às páleas do receptáculo, sem pápus Montanoa 23'. Páleas do receptáculo com ápice acuminado; todas as flores da mesma cor; cipselas prismáticas, 3-4-gonais, livres das páleas do receptáculo, pápus de cerdas decíduas

Melanthera

24. Cipselas com constrição na parte central, próxima ao ápice, formando um rostro curto ou, às vezes, inconspícuo, no qual estão inseridos os elementos do pápus (estrutura coroniforme ou de aristas) ........................ 25 24'. Cipselas sem constrição próxima ao ápice, sem rostro ......................... 30

25. Flores do raio neutras ou estéreis .............................................................. 26

25'. Flores do raio pistiladas ............................................................................ 27

26. Brácteas involucrais internas com estrias enegrecidas; corola das flores do disco com bainha de fibras ao longo das nervuras; cipselas clavadas com base atenuada, sem elaiossomos

Elaphandra

26'. Brácteas involucrais internas sem estrias enegrecidas; corola das flores do disco sem bainha de fibras ao longo das nervuras; cipselas cilíndricas, obovoides ou elipsoides, sem base atenuada, com elaiossomos Aspilia

27. Flores do raio inconspícuas; brácteas involucrais com estrias verdes (Figura 19H); páleas do receptáculo com ápice eroso truncado ... Blainvillea 27'. Flores do raio conspícuas; brácteas involucrais sem estrias verdes; páleas do receptáculo com ápice de outros tipos 28

28. Pápus de aristas decíduas Perymenium 28’. Pápus coroniforme persistente 29

29. Ervas geralmente prostradas; capítulos solitários; cipselas conspicuamente tuberculadas, rostro e pápus às vezes recobertos por um colar cortíceo contínuo com o corpo da cipsela (Figura 20E)

Sphagneticola

29'. Ervas geralmente eretas ou arbustos; capítulos raramente solitários; cipselas lisas ou apenas ligeiramente tuberculadas (Figura 20G); pápus não recoberto na maturidade. Wedelia 
30. Planta com ramos hirsutos; embrião proeminente no centro da cipsela e borda plana ao redor Simsia

30'. Plantas sem o conjunto de caracteres 31

31. Cipselas aladas (às vezes, somente as do raio) 32

31'. Cipselas sem alas. 34

32. Cipselas do raio com alas de margem lacerada (Figura 20F) e cipselas do disco sem alas Synedrella

32'. Cipselas do raio e do disco com alas de margem não lacerada 33

33. Brácteas involucrais da série externa patentes, semelhantes às folhas dos ramos; pápus de aristas com fitomelanina Dimerostemma 33'. Brácteas involucrais da série externa apressas ou reflexas; pápus de aristas sem fitomelanina Verbesina

34. Brácteas involucrais da série externa patentes, semelhantes às folhas dos ramos; pápus de aristas com fitomelanina Dimerostemma 34'. Brácteas involucrais da série externa apressas ou reflexas, escariosas ... 35

35. Flores do raio neutras 36

35'. Flores do raio pistiladas 38

36. Cipselas glabras ou pubescentes, sem pápus ou com pápus 2-aristado, decíduo, raramente com escamas intermediárias Helianthus 36'. Cipselas pilosas, pápus coroniforme ou 2-aristado persistente, geralmente com escamas intermediárias 37

37. Pedúnculo fistuloso e inflado abaixo do capítulo. Tithonia 37'. Pedúnculo cheio e não inflado abaixo do capítulo Aldama

38. Cipselas do disco obcônicas ou obpiramidais, pápus coroniforme de aristas muito curtas Baltimora 38'. Cipselas do disco compressas; pápus de aristas conspícuas

Calyptocarpus 


\section{Literatura recomendada}

ALVES, M.; ROQUE N. First record of Sclerocarpus africanus Jacq. (Asteraceae, Heliantheae) for South America. Check List, Porto Alegre, v. 12, n. 6, $2016 \mathrm{a}$.

ALVES, M.; ROQUE N. Flora da Bahia: Asteraceae - Tribo Heliantheae.

Sitientibus série Ciências Biológicas, Feira de Santana, v. 16, p. 1- 63, $2016 \mathrm{~b}$.

ARRAIGADA, J. E. Revision of the genus Clibadium (Asteraceae,

Heliantheae). Brittonia, Bronx, v. 55, p. 245-301, 2003.

BALDWIN, B. G. Heliantheae alliance FUNK, V. A. et al. (Ed.). Systematics, Evolution and Biogeography of Compositae. Vienna: IAPT, 2009.

p. 689-711.

BALDWIN, B. G.; WESSA, B. L; PANERO, J. L. Nuclear rDNA evidence for major lineages of helenioid Heliantheae (Compositae). Systematic Botany, Kent, v. 27, n. 1, p. 161-198, 2002.

BINNS, S. E.; BAUM B. R.; ARNASON J. T. A taxonomic revision of Echinacea (Asteraceae: Heliantheae). Systematic Botany, Kent, v. 27, n. 3, p. 610-632, 2002.

BOLICK, M. R. Systematics of Salmea DC. (Compositae: Heliantheae). Systematic Botany, Kent, v. 16, n. 3, p. 462-477, 1991.

BRINGEL JR., J. B. A. Contribuição ao estudo de Heliantheae (Asteraceae): revisão taxonômica e filogenia de Riencourtia Cass. 2015. 159 f. Tese (Doutorado em Botânica) - Universidade de Brasília, Brasília, DF, 2014.

CLEVINGER J. A.; PANERO J. L. Phylogenetic analysis of Silphium and subtribe Engelmanniinae (Asteraceae: Heliantheae) based on ITS and ETS sequence data. American Journal of Botany, Saint Louis, v. 87, p. 565-572, 2000 .

DELPRETE, P. G. Systematic study of the genus Delilia (Asteraceae, Heliantheae). Plant Systematics and Evolution, New York, v. 194, n. 1, p. 111-122, 1995. 
HIND, D. J. N. An annotated preliminary checklist of the Compositae of Bolivia (Version 2). 2011. Disponível em: < http://www.kew.org/science/tropamerica/ boliviacompositae/>. Acesso em: 12 maio 2017.

JANSEN, R. K. Systematics of Spilanthes (Compositae: Heliantheae). Systematic Botany, Kent, v. 6, n. 3, p. 231-157, 1981.

JANSEN, R. K. The systematics of Acmella (Asteraceae-Heliantheae). Systematic Botany Monographs, Ann Arbor, v. 8, p. 1-115, 1985.

KARIS, P. O. The Heliantheae sensu lato (Asteraceae), clades and classification. Plant Systematics and Evolution, New York, v. 188, n. 3/4 188, p. 139-195, 1993.

KARIS, P. O.; RYDING, O. Tribe Heliantheae. In: BREMER, K. (Ed). Asteraceaecladistics and classification. Portland: Timber Press.1994. p. 559-624.

LÖVE, D.; DANSEREAU, P. Biosystematic studies on Xanthium: taxonomic appraisal and ecological status. Canadian Journal of Botany, Ottawa, v. 37, n. 2, p. 173-208, 1959.

MAGENTA, M. A. G. Viguiera Kunth (Asteraceae, Heliantheae) na América do Sul e Sistemática das Espécies do Brasil. 2006. 399 f. Tese (Doutorado em Botânica) Instituto de Biociências Universidade de São Paulo, São Paulo, 2006.

MAGENTA, M. A. G.; PIRANI, J. R. Novidades taxonômicas em Aldama (Asteraceae-Heliantheae). Rodriguésia, Rio de Janeiro, v. 65, n. 1, p. 175-192, 2014.

MONDIN, C. A. Levantamento da Tribo Heliantheae Cass. (Asteraceae), sensu stricto, no Rio Grande do Sul, Brasil. 2004. 353 f. Tese (Doutorado em em Botânica) - Universidade Federal do Rio Grande do Sul, Porto Alegre, 2004.

MORAES, M. D.; SEMIR J. A revision of Brazilian Dimerostemma (Asteraceae, Heliantheae, Ecliptinae), with a new species and taxonomic adjustments. Brittonia, Bronx, v. 61, n. 4, p. 341-365, 2009.

ORCHARD, A. E.; CROSS, E. W. A revision of the Australian species of Eclipta (Asteraceae: Ecliptinae), with discussion of extra-Australian taxa. Nuytsia, South Perth, v. 23, n. 1, p. 43-62, 2013. 
PANERO, J. L. Tribe Helenieae Cass. In: KUBITZKI, K.; JEFFREY, C. (Ed.). The Families and Genera of Vascular Plant: v. VIII: Flowering Plants Eudicots: Asterales. Berlin: Springer-Verlag, 2007. p. 400-406.

PANERO, J. L. et al. Molecular phylogenetic studies of members of tribes Helenieae, Heliantheae and Eupatorieae (Asteraceae). 2. Tribal/ generic relationships. In: OSBORN J. M. (Ed.). Botany 2001, Abstracts, part 3. Systematics. Saint Louis: Botanical Society of America, 2001.

PANERO, J. L., JANSEN, R. K.; LEVINGER, J. A. C. Phylogenetic relationships of the subtribe Ecliptinae (Asteraceae - Heliantheae) based on chloroplast DNA restriction site data. American Journal of Botany, Saint Louis, v. 86, p. 413-427, 1999.

PANERO, J. L.; FUNK, V. A. Toward a phylogenetic subfamilial classification for the Compositae (Asteraceae). Proceedings of the Biological Society of Washington, Washington, v. 115, n. 4, p. 909-922, 2002.

PARKS, J. C. A revision of North American and Caribbean Melanthera (Compositae). Rhodora, Cambridge, v. 75, n. 802, p. 169-210, 1973.

PAYNE, W. W. A re-evaluation of the genus Ambrosia (Compositae). Journal of the Arnold Arboretu, Cambridge, v. 45, p. 401-438, 1964.

PRUSKI, J. F. Compositae of the Guayana Highland-XI. Tuberculocarpus gen. nov. and some other Ecliptinae (Heliantheae). Novon, Saint Louisv. 6, n. 4, p. 404-418, 1996.

ROBINSON, H. New combinations in Elaphandra Strother (EcliptinaeHeliantheae-Asteraceae). Phytologia, Huntsville, v. 72, p. 144-151, 1992. ROBINSON, H. A revision of the tribal and subtribal limits of the Heliantheae (Asteraceae). Washington : Smithsonian Institution Press,1981. (Smithsonian Contributions to Botany, v. 51).

SANTOS, J. U. 0 gênero Aspilia Thouars no Brasil. Belém: Funtec, 2001.

SEMPLE, J. C. A Revision of the Genus Borrichia Adans. (Compositae). Annals of the Missouri Botanical Garden, v. 65, n. 2, p. 681-693, 1978.

SILVA, G. A. R.; SANTOS, J. U. Novos registros de espécies da subtribo Ecliptinae (Heliantheae-Asteraceae) para a Amazônia brasileira. Acta Amazonica, Manaus, v. 40, n. 3, p. 499-508, 2010. 
SHERFF, E. E. The genus Bidens. Field Museum of Natural History, Botanical Series, Chicago, v. 16, p. 1-709, 1937.

SCHILLING, E. E.; PANERO, J. L. A revised classification of subtribe Helianthinae (Asteraceae: Heliantheae) II. Derived Lineages. Botanical Journal of the Linnean Society, London, v. 167, n. 3, p. 311-331, 2011.

SPOONER, D. M. Systematics of Simsia (Compositae-Heliantheae). Systematic Botany Monographs, Ann Arbor, v. 30, p. 1-90, 1990.

STROTHER, J. L. Oblivia, a new genus for Zexmenia mikanioides (Compositae: Heliantheae). Systematic Botany, Kent, v. 14, n. 4, p. 541-543, 1989.

STUESSY, T. F. Revision of the genus Baltimora (Compositae, Heliantheae). Field Museum of Natural History, Botanical Series, Chicago, v. 36, n. 5, 1973.

STUESSY, T. F. Heliantheae - systematic reviewin. In: HEYWOOD, V. H.; HARBORNE, J. B.; TURNER, B. L. (Ed.). The Biology and chemistry of the Compositae. London: Academic Press, 1977. p. 621-671,

STUESSY, T. F. Revision of Lagascea (Compositae, Heliantheae). Chicago: Field Museum of Natural History, 1978. (Fieldiana., Botany v. 38, n. 8).

TORRES, A. M. Revision of Sanvitalia (Compositae-Heliantheae). Brittonia, Bronx, v. 16, n. 4, p. 417-433, 1964.

TORRES, A. M. Revision of Jaegeria (Compositae-Heliantheae). Brittonia, Bronx, v. 20, p. 52-73, 1968.

Turner, B. L. Taxonomic study of the genus Synedrella (AsteraceaeHeliantheae). Phytologia, Huntsville, v. 76, n. 1, p. 39-51, 1994.

TURNER, B. L.; POWELL, A. M. Helenieae - systematic review. In: HARBORNE, J.; TURNER, B. L; HEYWOOD, V. (Ed.). The biology and chemistry of the Compositae. London: Academic Press, 1977. p. 699-737.

URBATSCH, L. E.; BALDWIN B. G.; DONOGHUE M. J. Phylogeny of the Coneflowers and relatives (Heliantheae: Asteraceae). Systematic Botany, Kent, v. 25, n. 3, p. 539-565, 2000. 